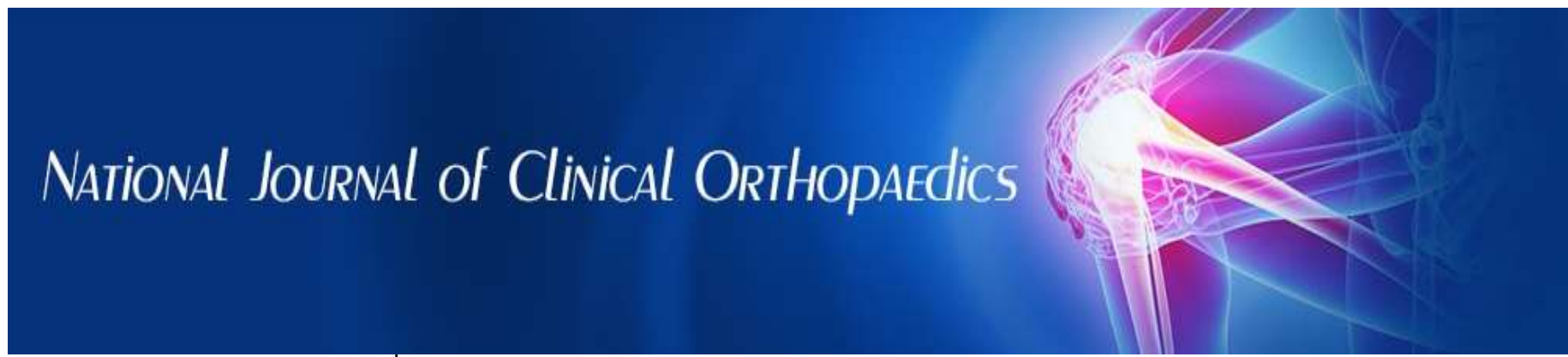

ISSN (P): 2521-3466

ISSN (E): 2521-3474

(C) Clinical Orthopaedics

www.orthoresearchjournal.com

2021; 5(1): 77-79

Received: 17-11-2020

Accepted: 08-12-2020

Mojahid KS Alshammaa

Nineveh Health Directorate,

Mosul, Iraq

Nashae Alhafid

Nineveh Health Directorate,

Mosul, Iraq

Emad YM Alsikilli

Nineveh Health Directorate,

Mosul, Iraq

Asmaa Nashae Alhafid

Nineveh Health Directorate,

Mosul, Iraq
Corresponding Author:

Mosul, Iraq

\section{Osteophytes above fifty years, prospective study}

\section{Mojahid KS Alshammaa, Nashae Alhafid, Emad YM Alsikilli and Asmaa Nashae Alhafid}

DOI: https://doi.org/10.33545/orthor.2021.v5.i1b.262

\section{Abstract}

Objectives: The purpose of this study is to determine whether osteophytes are part of aging process or a cause of disease.

Patients and Methods: This was observational study of 226 cases, lasted from June 2018 to March 2019, they were (71) male and (155) female, (mean 1.69), ranging in age from (2-81) years, (mean 45.99). Referred from outpatient clinic from Ibn Sina teaching hospital to radiology department, in Mosul city, having different complaints of pain including cervical pain, backache, knee pain, heel pain, trauma, fall from height, motorcycle accident, and other painful conditions.

Results: We found three groups of patients, group 1 ( $<25$ years) had no osteophytes, group 2 (26-49 years) had osteophytes less than osteophytes of group 3 ( $>50$ years).

Conclusion: Osteophytes are common above age of 50 years, not because of disease but coming with age.

Keywords: Osteophytes, disease, backache

\section{Introduction}

Being the most common musculoskeletal progressive condition, It is estimated that the prevalence of knee osteoarthritis among adults 60 years of age or older is approximately $10 \%$ in men and $13 \%$ in women, making knee osteoarthritis one of the leading causes of disability in elderly population ${ }^{[1]}$. An osteophyte is 'a fibrocartilage- capped bony outgrowth.

There are three types of osteophytes:

1. The traction osteophytes at the insertion of tendons and ligaments.

2. The inflammatory osteophytes, represented by the syndesmophyte at the insertion of ligaments and tendons bone as can be seen in ankylosing spondylitis; and

3. The genuine osteophyte or osteochondrophyte (chondro-osteophyte) arising in the periosteum overlying the bone at the junction between cartilage and bone ${ }^{[2]}$.

We shall talk about genuine osteophyte, which occur with age. We did this study because we think the osteophytes are aging process and not the cause of disease, this process is going on in our body with age such as loss of elasticity in blood vessels (atherosclerosis) and loss of elasticity in tendons and whitening of the hair. According to ACR criteria of osteoarthritis, all patients should be above 50 years to enter the criteria. Presence of knee pain along with at least three of the following six items can classify the knee osteoarthritis in the patients ${ }^{[3]}$.

- Age $>50$ years old

- Morning stiffness $<30$ minutes

- Crepitus on knee motion

- Bony tenderness

- Bony enlargement

- No palpable warmth

In addition, many doctors have the idea 'if there is joint pain, they call it 'osteoarthritis' even if patient is young (below $25 \mathrm{y}$ ), so the patient puts the idea in his mind (I have osteoarthritis). 
Literature review: In pathophysiology of osteophytes; when articular cartilage prone to damage, by wear and tear or other pathology, transforming growth factor- $\beta$ promotes cartilage repair resulting in endochondral ossification and osteophyte formation ${ }^{[4]}$. More severe cartilage lesions were associated with larger osteophyte size ${ }^{[5]}$.

In knee osteoarthritis, osteophytes bring stability to knee by increasing the joint surface area ${ }^{[6]}$. Age estimation from skeletal remains important step in forensic biological identification [7], they use 'age estimation equations' by calculating the length of vertebral osteophytes' so osteophytes not appear at younger age groups.

They appear from 22 years in cadaver not in X-rays. Aging changes in the musculoskeletal system increase the propensity to osteoarthritis but the joints affected and the severity of disease closely related to other osteoarthritis risk factors such as joint injury, obesity, genetics, and anatomical factors that affect joint mechanics ${ }^{[8]}$. A great number of individuals with structural osteoarthritic joint changes have few or no symptoms [9], furthermore, radiologic spondylotic changes increase with patient age; $70 \%$ of asymptomatic persons older than 70 years have some form of degenerative change in the cervical spine ${ }^{[10]}$. Several studies have found an association between lumbar spondylosis and low back pain, but others have not. Whether lumbar spondylosis causes low back pain remains controversial ${ }^{[11]}$, and There are mixed evidence for the association of lumbar disc degeneration with chronic mechanical low back pain and disability ${ }^{[12]}$. Most older participants with a high suspicion for clinical hip osteoarthritis (groin or anterior thigh pain and/or painful internal rotation) did not have radiographic hip osteoarthritis, suggesting that in many cases, hip osteoarthritis might be missed if diagnosticians relied solely on hip radiographs ${ }^{[13]}$.

\section{Patients and Methods}

Lain X-Rays of the cervical, or lumbar spines, or both knee joints, or both heels of (226) patients were included in this study. They were (72) male and (154) female. Ranging (2-81) years mean (45.99), patients were referred to the Radiology Department of Ibn Sina Teaching Hospital in Mosul city from the Outpatient Department coming for different complaints including cervical pain, backache, knee pain, heel pain, trauma, fall from height, motorcycle accident, and other complain conditions.

Those patients examined by X-ray machine ECORAY of 125 $\mathrm{KV} \& 500 \mathrm{~mA}$ \& processed by $\mathrm{CR}$ machine Carestem radiographs judged positive for osteophyte when they showed definite bony projection from articular surface of the previous mentioned joints of one or more vertebrae or knee joint or calcaneus bone. Specialist in radiology examined all the films carefully. A full record of the patient's complaints, the result. of the examination are put in schedule shared with other researcher by net, the full name, age, complain, area of examination, positive \& negative result are included and divided into 3 groups.

Statistical tests using descriptive statistics including, means, standard deviations, and spearman's rho correlation test, we defined $P<0.05$. Significant. All statistical analyses were performed using the SPSS software package (SPSS for Windows, version 25, IBM Corp., Armonk, NY, USA).

Results: we divided patients into three age groups.

1. Group 1; all (37) patients below 25 years of (48), body sites had no osteophytes, as shown in table below.

Table 1: Number of patients.

\begin{tabular}{|llll|}
\hline Descriptive Statistics & & \\
& $\mathrm{N}$ & Mean & Std. Deviation \\
\hline Gender & 37 & 1.57 & .502 \\
C. spine & 8 & 1.00 & .000 \\
L spine & 17 & 1.00 & .000 \\
R knee & 3 & 1.00 & .000 \\
L knee & 0 & & \\
R heel & 7 & 1.00 & .000 \\
L heel & 7 & 1.00 & .000 \\
Valid N (listwise) & 0 & & \\
\hline
\end{tabular}

2. Group 2; (60) patients between (26-49) years, having no osteophytes in more than half of them, all complaining of pain.

Table 2: Gender and Age group.

\begin{tabular}{|c|c|c|c|c|}
\hline \multicolumn{5}{|c|}{ Gender * Osteophytes Group $2(26-49)$ Years } \\
\hline \multicolumn{5}{|c|}{ Count } \\
\hline & & \multicolumn{2}{|c|}{ Osteophytes } & \multirow{2}{*}{ Total } \\
\hline & & $\mathbf{N}$ & $\mathbf{P}$ & \\
\hline \multirow{2}{*}{ Gender } & Male & 17 & 5 & 22 \\
\hline & Female & 35 & 23 & 58 \\
\hline \multicolumn{2}{|c|}{ Total } & 52 & 28 & 80 \\
\hline
\end{tabular}

3. Group 3: patients above 50 years were 129 patients, osteophytes seen in multiple body areas, osteophytes seen in 123 body sites. \& no osteophytes seen in 50 areas of body of painful cervical, lumber, knees or heels.

Table 3: Gender and age above fifty years.

\begin{tabular}{|c|c|c|c|c|}
\hline \multicolumn{5}{|c|}{ Gender * Osteophytes Above 50 Years } \\
\hline \multicolumn{5}{|c|}{ Count } \\
\hline & & $\mathbf{N}$ & $\mathbf{P}$ & Total \\
\hline \multirow{2}{*}{ Gender } & Male & 12 & 30 & 42 \\
\hline & Female & 38 & 93 & 131 \\
\hline \multicolumn{2}{|c|}{ Total } & 50 & 123 & 173 \\
\hline
\end{tabular}

In comparing presence of osteophytes between group2 and group 3 , P value (>.000) was highly significant between them. 
Table 4: Correlation, Coefficient.

\begin{tabular}{|c|c|c|c|c|c|}
\hline & & & gender & osteophytes & FREQ \\
\hline \multirow[t]{10}{*}{ Spearman's tho } & \multirow[t]{3}{*}{ gender } & $\begin{array}{l}\text { Correlation } \\
\text { Coefficient }\end{array}$ & 1.000 & .000 & $.801^{\prime \prime}$ \\
\hline & & Sig. (2-tailed) & . & .998 & .000 \\
\hline & & $\mathrm{N}$ & 253 & 253 & 253 \\
\hline & \multirow[t]{3}{*}{$\begin{array}{l}\text { osteophyte } \\
\mathrm{s}\end{array}$} & $\begin{array}{l}\text { Correlation } \\
\text { Coefficient }\end{array}$ & .000 & 1.000 & .392 \\
\hline & & Sig. (2-tailed) & .998 & . & .000 \\
\hline & & $\mathrm{N}$ & 253 & 253 & 253 \\
\hline & \multirow[t]{4}{*}{ FREQ } & $\begin{array}{l}\text { Correlation } \\
\text { Coefficient }\end{array}$ & $.801^{\circ}$ & $.392^{-}$ & 1.000 \\
\hline & & Sig. (2-tailed) & .000 & .000 & \\
\hline & & & & & + \\
\hline & & $\mathrm{N}$ & 253 & 253 & 253 \\
\hline
\end{tabular}

\section{Discussion}

All (37) patients below 25 years of (48), body sites had no osteophytes; we could not found similar study, to compare it to our results, which may be present, Also number below 25 years was too small to decide 'no osteophytes below this age' and need larger number. In Group 2; (60) patients between (26-49) years, all complaining of pain but having no osteophytes in more than half of them, 52 body areas having no osteophytes and 28 have osteophytes, these results was similar to results of Abdus Salam et al. who examined (1000) cervical spine x-ray and found that "correlation between the degree of radiographic changes and severity of pain is poor" ${ }^{[14]}$. In lumber region, there are many sources of pain, vertebral discs, neural compression, intervertebral ligaments, facet joints, ligamentous sprain, muscle spasm, sacroiliac joints, defects of the lumbar pars interarticularis ( $8 \%$ of back pain) or others, according to the Arthritis Foundation, spinal osteoarthritis may affect as many as $75 \%$ of everyone over the age of $60^{[15]}$. Posterior vertebral osteophytes are less common and only rarely impinge upon the spinal cord or nerve roots ${ }^{[15]}$. Also in DISH, the patient may has no pain, but the X-ray shows features of ankylosing spondylitis due to heavy osteophytes. Furthermore, same thing happen for knee pain, 'pain in one knee which is in grade 2 and other knee in grade 3 (osteophytes with narrowing joint space, but without pain'. This was also seen in conclusion study conducted by Ali Guermazi et $a l . ;$ 'MRI shows prevalence of at least one type of MRI detected pathology ("any abnormality") was high in both painful (91\%) and painless $(88 \%)$ knees. Regardless of the definition of pain used ${ }^{[16]}$. Furthermore, in a good number of patients, we found right heel pain (they call it calcaneal spur) has osteophytes and other heel has spur too, so osteophytes maybe not related to pain, or we found the painful foot has no osteophyte and the other silent heel has osteophytes. Draghi et al. were concluded that the key radiological features that differentiate the groups were not spurs but rather changes in the soft tissues ${ }^{[17]}$.

\section{Conclusion}

Osteophytes are common above age of 50 years, not because of disease but coming with age.

\section{References}

1. Primorac D, Molnar V, Rod E, Jeleč Ž, Čukelj F, Matišić V, et al. Knee Osteoarthritis. Review of Pathogenesis and State-Of-The-Art Non-Operative Therapeutic Considerations. Genes 2020;11(8):854.

2. van der Kraan PM, van den Berg WB. Osteophytes: relevance and biology. Osteoarthritis Cartilage 2007;15(3):237-44.
3. ACR Revised Criteria for Early Diagnosis of Knee Osteoarthritis. Autoimmune Dis Ther Approaches Open Access 2016;3(1).

4. Shin CS, Lee JH. Arthroscopic Treatment for Osteoarthritic Knee. Knee Surg Relat Res 2012;24(4):187-92.

5. Markhardt BK, Li G, Kijowski R. The Clinical Significance of Osteophytes in Compartments of the Knee Joint With Normal Articular Cartilage. Am J Roentgenol 2018;210(4):W164-71.

6. Krishna Avulapati S, Orthopedics SMV Orthopedics, Sunil B Orthopedics, et al. Osteophytes in Knee - How large they can be? Indian J Orthop Surg 2020;5(4):292-5.

7. Praneatpolgrang S, Prasitwattanaseree S, Mahakkanukrauh P. Age estimation equations using vertebral osteophyte formation in a Thai population: comparison and modified osteophyte scoring method. Anat Cell Biol 2019;52(2):149.

8. Shane Anderson A, Loeser RF. Why is osteoarthritis an age-related disease? Best Pract Res Clin Rheumatol 2010;24(1):15-26.

9. Amoako AO, Pujalte GGA. Osteoarthritis in Young, Active, and Athletic Individuals. Clin Med Insights Arthritis Musculoskelet Disord 2014:CMAMD.S14386.

10. How does the incidence of cervical spondylosis vary by age_.pdf.

11. Tsujimoto R. Prevalence of lumbar spondylosis and its association with low back pain among community-dwelling Japanese women 2016, 7.

12. Perera RS, Dissanayake PH, Senarath U, Wijayaratne LS, Karunanayake AL, Dissanayake VHW, et al. Associations between disc space narrowing, anterior osteophytes and disability in chronic mechanical low back pain: a cross sectional study. BMC Musculoskelet Disord 2017;18(1):193.

13. Kim C, Nevitt MC, Niu J, Clancy MM, Lane NE, Link TM, et al. Association of hip pain with radiographic evidence of hip osteoarthritis: diagnostic test study. BMJ 2015; h5983.

14. Radiographic evaluation of cervical spine.pdf.

15. Eidelson WSG, Erdelyi KM, Kim RCW. Spondylosis Symptoms, Causes, Diagnosis and Treatment 6.

16. Guermazi A, Niu J, Hayashi D, Roemer FW, Englund M, Neogi $\mathrm{T}$, et al. Prevalence of abnormalities in knees detected by MRI in adults without knee osteoarthritis: population based observational study (Framingham Osteoarthritis Study). BMJ 2012;345(1):e5339-e5339.

17. Draghi F, Gitto S, Bortolotto C, Draghi AG, Ori Belometti G. Imaging of plantar fascia disorders: findings on plain radiography, ultrasound and magnetic resonance imaging. Insights Imaging 2017;8(1):69-78. 